\title{
HIV/Aids: \\ Percepções, Significados e Consequências da Assistência de Trabalhadores da Saúde da Família
}

\author{
Kemily Benini Costa ${ }^{1}$, Yaisa França Formenton ${ }^{2}$, Marcia Niituma Ogata ${ }^{3}$
}

\begin{abstract}
RESUMO
O presente estudo tem como objetivo analisar as percepções e significados de HIV/Aids de trabalhadores da saúde da família e as consequências de sua assistência às pessoas que convivem com a infecção. Trata-se de uma pesquisa qualitativa, desenvolvida com os 14 profissionais da equipe multiprofissional da Estratégia Saúde da Família num município paulista. Os dados foram coletados por entrevista semiestruturada e interpretados por análise de conteúdo. Construíram-se três categorias de análise. 1. Relação com o cuidado, em que o HIV/Aids refere-se à condição de anormalidade; 2 . Impacto individual, familiar e social, marcado pelo preconceito e julgamento pela forma de contágio; e 3. HIV/Aids e sexualidade, prevalecendo como causa de contaminação os atos sexuais ilícitos e a quantidade de parceiros, bem como a culpabilização da pessoa a adquirir a condição. Apesar das mudanças no perfil epidemiológico da doença ao longo do tempo e introdução da terapia antirretroviral, os profissionais reproduzem e carregam percepções estigmatizantes resultando em discursos falsamente modificados, que trazem à tona simbolismos primários da infecção relacionados ao incorreto, ao medo e ao preconceito. A percepção e significados atribuídos podem refletir na sua prática de cuidado, impactando na eficácia da atenção integral à saúde.
\end{abstract}

Palavras-chave: Profissional de saúde. HIV. Aids. Percepções.

HIV/AIDS: PERCEPTIONS, MEANINGS AND CONSEQUENCES OF THE ASSISTANCE OF FAMILY HEALTH WORKERS

\section{ABSTRACT}

The study aims to analyze the perceptions and meanings of HIV/Aids among family health workers and the consequences of assisting people living with the infection. It is a qualitative research, developed with the 14 professionals of the multi-professional team of the Family Health Strategy in a city of São Paulo. The data were collected by semi-structured interview and interpreted by content analysis. Three categories of analysis were constructed. 1. Relationship with care in which HIV/Aids refers to the condition of abnormality; 2 . Individual, family and social impact marked by prejudice and judgment by the form of contagion and 3. HIV/Aids and sexuality in prevails as a cause of contamination the illicit sexual acts and the amount of partners, as well as blaming the person to acquire the condition. It is observed a predominance of the permanence of group concepts and risk behavior. Despite changes in the epidemiological profile of the disease over time and the introduction of antiretroviral therapy, professionals reproduce and carry stigmatizing perceptions resulting in falsely modified discourses that bring to the surface primary symbolisms of infection related to incorrectness, fear, and prejudice. The perception and meanings attributed can reflect in their care practice impacting on the effectiveness of integral health care.

Keywords: Health personnel. HIV. Aids. Perceptions.

\footnotetext{
Enfermeira. Bacharelado com formação pedagógica complementar pela Universidade Federal de São Carlos (UFSCar, 2018). Mestranda em Ciências da Saúde na Universidade Federal de São Carlos, cursando especialização em enfermagem obstétrica no Centro Universitário Adventista de São Paulo (Unasp, 2019). http://lattes.cnpq.br/1424644730814556. http://orcid.org/0000-0003-1410-7637. kemilybcosta@gmail.com

2 Graduação em Enfermagem (2005). Mestrado em Enfermagem pela Universidade Federal de São Carlos (2013). Atualmente está cursando o doutoramento pelo Programa de Pós-Graduação em Enfermagem pela Universidade Federal de São Carlos e atua como enfermeira na Unidade de Cuidado à Criança do Hospital Universitário da UFSCar pela empresa EBSERH. http://lattes.cnpq.br/9720418588709046. https://orcid.org/0000-0002-7028-6935. yaisafranca@ gmail.com

${ }^{3}$ Doutorado em Enfermagem Fundamental pela Universidade de São Paulo, Brasil (2000). Professora titular da Universidade Federal de São Carlos, Brasil. http://lattes.cnpq.br/3274294833403570. http://orcid.org/0000-0001-8390-7334. marciaogata1964@gmail.com
} 


\section{INTRODUÇÃO}

A Síndrome da Imunodeficiência Adquirida (Aids), causada pelo vírus da imunodeficiência adquirida (HIV) (CALIARI et al., 2017), exerce, ainda, em detrimento da evolução e organização dos serviços e políticas de saúde, bem como da aquisição da terapia antirretroviral de alta potência introduzida na década de 90 do século 20 (GUIMARÃES et al., 2017), grande impacto na saúde pública mundial e brasileira em razão da sua gravidade e caráter pandêmico (BRANDÃO et al., 2017). Em 2018 em torno de 37,9 milhões de pessoas viviam com HIV/Aids, posto que, neste mesmo ano, houve 1,7 milhões de casos novos e 777 mil mortes relatadas pela doença no mundo (UNAIDS, 2019).

Desde seu surgimento, o vírus foi permeado por preconceito e estigma, fundamentado no público principal que atingia - homossexuais, profissionais do sexo e usuários de drogas -, grupos marginalizados da sociedade (MOREIRA et al., 2010). Firmou-se o entendimento dessa condição como resultado de atos e comportamentos reprováveis, pertencentes a indivíduos específicos considerados responsáveis pela exposição ao vírus e adoecimento (VILIARINHO; PADILHA, 2014). Todo esse contexto, somado à exacerbada manifestação orgânica, culminou na construção de percepções comuns em relação à doença alicerçadas no medo, na morte e no sofrimento (DANTAS et al., 2014).

Tais percepções não podem ser negadas, pois são inerentes à condição do ser humano. São construídas socialmente e vão determinar como os indivíduos estarão preparados para perceber o mundo e agir perante ele (MORIN, 2011). A existência de estigma perante o HIV/Aids influencia diretamente na assistência prestada e no relacionamento profissional-usuário (SILVA et al., 2017). Isso também acaba por moldar atos verbais e não verbais de descaso, julgamento, reprovação e preconceito, resultando em comprometimento do vínculo ou criação do mesmo. Abre-se, então, espaço para o surgimento de desconfiança, angústia e resistência à procura de serviços de saúde, que, ao afetar a adesão ao tratamento, autocuidado, educação em saúde e corresponsabilização, fragilizam a qualidade e eficácia do cuidado, da promoção e da prevenção da saúde (NYBLADE et al., 2019).

A Estratégia Saúde da Família (ESF), instituída como modelo para a reorganização da prática assistencial do Sistema Único de Saúde (SUS) (ZAMBENEDETTI; BOTH, 2013), a partir de seus pressupostos de territorialização, população adscrita e criação de vínculo (CACCIA-BAVA; MATTOS; ROCHA, 2012), tem papel fundamental em oferecer um cuidado integral e longitudinal à pessoa que convive com HIV/Aids, bem como estabelecer sentido a estas ações à medida que se desenvolve confiança (ARANTES; SHIMIZU; MERCHAN-HAMANN, 2016) Ainda, por ser a principal porta de entrada e coordenadora dos serviços de saúde (CACCIA-BAVA; MATTOS; ROCHA, 2012) tem papel primordial na prevenção da doença, diagnóstico e tratamento precoce.

No que se refere ao estudo das percepções dos profissionais da Saúde da Família, deve-se considerar que a epidemia do HIV/Aids apresentou mudanças significativas ao longo do tempo, com aumento progressivo da contaminação de mulheres, disseminação para coletivos de menor escolaridade e predomínio da transmissão heterossexual, contrapondo-se aos caracteres dos anos 80 do século 20, composto, predominantemente, por homens e transmissão homossexual (SILVA et al., 2017). Acredita-se, ainda, num atual movimento de superação da imagem degradante daquele que convive com HIV/Aids, sobretudo com a eficácia da terapia antirretroviral, aumento da expectativa e qualidade de vida e mudança no perfil epidemiológico da doença (LEAL; COÊLHO, 2016).

Essa nova conformação do HIV/Aids, juntamente com o ideal de mudança do perfil assistencial e introdução do cuidado integral ao usuário, tornou inquietante analisar quais são as percepções e significados dos profissionais de Saúde da Família de HIV/ Aids, bem como sua influência no cuidado oferecido às pessoas que convivem com essa condição, promovendo reflexão sobre a atuação desses profissionais na garantia dos princípios do SUS e de uma assistência acolhedora, humanizada e integral.

\section{METODOLOGIA}

Trata-se de uma pesquisa qualitativa, desenvolvida em uma Unidade Saúde da Família (USF), com equipe completa, atuante num território de vulnerabilidade social marcado pela violência, baixa condição socioeconômica, pontos de venda e usuários de droga em um município paulista. A coleta de dados ocorreu de maio a junho de 2017 por uma única pesquisadora, que teve o preparo adequado para sua realização por meio de leituras sobre o tema, discussões com professores e exercício prático. $O$ método escolhido foi a entrevista semiestruturada, fundamentada em questões abertas e norteadoras, primeiramente validadas por entrevista piloto com profissional de diferentes USFs do município. As entrevistas, propriamente ditas, foram áudiogravadas e conduzidas na própria USF de 
investigação de acordo com a disponibilidade de seus integrantes, e teve duração média de 40 minutos. Os sujeitos do presente estudo foram 14 profissionais de saúde que compõem a equipe da unidade, sendo 8 agentes comunitários de saúde, 2 auxiliares de enfermagem, 1 enfermeiro, 1 dentista, u11m auxiliar de saúde bucal e 1 médico.

O projeto teve aprovação do Comitê de Ética em Pesquisa com seres humanos da UFSCar, sob parecer 1.991.756. As entrevistas foram realizadas individualmente, em horário previamente determinado, e áudiogravadas no próprio ambiente de trabalho. Estas somente tiveram início após a apresentação do objetivo do estudo pela pesquisadora a cada sujeito e do aceite em participar da pesquisa com a assinatura do Termo de Consentimento Livre e Esclarecido. As mesmas foram transcritas e analisadas exaustivamente, utilizando a análise de conteúdo temático-categorial (OLIVEIRA, 2008).

Houve a construção de tabelas de dados para comparação e identificação das abordagens mais frequentes e significativas de acordo com os objetivos do estudo. Após marcação das unidades de registro que sintetizam os aspectos referidos nas entrevistas, foram identificadas as unidades temáticas resultante do agrupamento de conteúdos convergentes. Os sentidos atribuídos dessas unidades acabaram por definir as categorias temáticas empíricas e discutidas com a literatura, a partir da revisão bibliográfica realizada anteriormente (OLIVEIRA, 2008).

\section{RESULTADOS}

A partir da análise de conteúdo temático-categorial das entrevistas, foram identificadas três categorias (Relação com o cuidado; Impacto individual, familiar e social do HIV/Aids e HIV/Aids e a sexualidade), apresentadas a seguir:

\section{Relação com o cuidado}

Conhecer as emoções dos profissionais ante a infecção reflete no entendimento de suas percepções sobre a mesma, bem como na construção social na qual baseiam suas ações. Majoritariamente, os sentimentos verbalizados ao cuidar de uma pessoa que convive com HIV/Aids foi referido como "normal", aparentemente igual àqueles que permeiam as relações de cuidado com qualquer outro usuário.

Nossa pra mim é normal [...] pra mim não tem nenhuma diferença (ACS- 6).
Normal [...] não posso ver eles só como soropositivo, tem que ver como um ser humano (ENF-10).

Esse aspecto de normalidade repetiu-se quanto ao cuidado que deve ser oferecido a tais indivíduos. Em sua análise, entretanto, esses discursos parecem declarar o oposto, a saber: significados de "anormalidade" das pessoas que convivem com HIV/Aids e de seu tratamento. É preciso esforçar-se para que o cuidado seja "normal" e, portanto, o sujeito que o recebe não é considerado como tal. Somam-se, ainda, falas explícitas que confirmam essa percepção.

O cuidado oferecido normalmente no dia a dia tem que ser normal, com carinho e tratar bem e deixar a pessoa ciente que ela tem que continua tomando os medicamentos, mas o contato é normal desde que não seja sexualmente ou contatos né, que venha passar pra outra pessoa, mas praticamente normal (AXE-9).

Olha eu acho que tem que ser o mais natural possível, eu acho que eles têm prioridade, pra mim eles têm prioridade [...] (D-8).

A partir do momento que você contrai o vírus você já não é a mesma pessoa [...] quer dizer, por mais que você se ache normal você não vai ser (ACS-1).

O processo de cuidar, embora apresente a ênfase da inclusão familiar e educação em saúde, permanece tendencioso ao modelo biomédico centrado na patologia, consultas e medicações, nos fatores que envolvem a transmissão e contágio da doença, bem como preocupação não com a pessoa que vive com HIV/Aids, mas com quem convive com ela.

Mas eu acho que a gente tem que abordar também a família; vamos trazer sua família pra que ela possa ajudar, pra que essa família seja munida de informações (ACS-3).

Tem que ter o acompanhamento psicológico, acompanhamento familiar (ENF-10).

Tratamento né, as consultas de rotina, os medicamentos né [...] se tiver parceiros, orientar como lidar com esse parceiro entendeu (AXE-14).

Ela precisa manter o acompanhamento na área da saúde, manter as medicações, e, mesmo que a pessoa doente vai ter a relação sexual, ela tem que se proteger [...] o uso das medicações né, a priori apresenta muitas reações (M-13).

Minha primeira preocupação né, é do parceiro dela né [...] se ele tem, se ele não tem, se ela contô pra ele né, e os cuidados que ela tem que tê com ele né (ACS-6). 
Ademais, parte dos entrevistados inferiu que os equipamentos de proteção individual (EPIs) utilizados para atendimento a todos os usuários são redobrados diante de indivíduos que convivem com a infecção, instaurando-se, assim, um cuidado diferenciado, que utiliza de maior segurança para assistência.

A gente acaba, às vezes, o curativo, assim, o Papanicolau, colocando duas luvas né [...] que às vezes as pessoas vem falá sou soropositivo $e$ acaba colocando por medo de exposição mesmo (ENF-10).

\section{Impacto individual, familiar e social do HIV/Aids}

Conviver com HIV/Aids foi considerado penoso e difícil, por afetar a saúde integral do usuário, exigir tratamento medicamentoso contínuo com possibilidade de efeitos colaterais e denotar uma ideia de morte ou perda de qualidade de vida. Além disso, a comparação da infecção com o câncer foi recorrente, modulada pela vivência da equipe com essa doença, experimentada com familiares e amigos próximos. Mesmo que o câncer venha, em alguns trechos, de modo a diminuir a carga negativa do HIV, a associação denota a existência de significados e manifestações que permutam entre as condições.

Angústia, aflição, medo né, é uma carga emocional muito grande (D-8).

Que vai morrer, o impacto mais forte assim né (ACS 11).

Pra pessoa, eu imagino que é muito difícil porque, assim, a pessoa que vive ela vai ser informada de que ela vai ter uma vida ali baseada naquelas medicações né (...) as reações adversas (ACS-3).

É como se tivesse dado uma notícia, como se a pessoa tivesse com câncer; ela já vê assim, um fim de linha entendeu (AXE-9).

As pessoas, assim, tão recebendo mais fácil o diagnóstico que está com HIV do que está com câncer (ACS-12).

Para os profissionais de saúde, o principal obstáculo em conviver com HIV/Aids é o preconceito e consequente exclusão. Nesse contexto, a família é amplamente citada como fonte de estigma, despertado, sobretudo, pela inquietação na forma de contágio. Reconhecem, entretanto, que ela também recebe o impacto da infecção e é considerada com papel essencial para afastar a discriminação e potencializar o cuidado integral à pessoa que convive com HIV/Aids.
Como vai pegar, como que não vai, o que eu posso fazer, que que eu não posso, ai é complicado, tem o preconceito sim. É a falta de informação (AXB-7).

Eu acho que o impacto vai variar da família descobrir qual foi a forma que; a primeira coisa que ela se contaminou, é usuário de droga? Se se relacionou com alguém que tinha e não sabia e pego, é, entendeu? Então assim vai variar, mas eu acho que de impacto, a família toma junto (ACS-5).

Ainda há muita discriminação ainda pela própria família [...] porque as pessoas ainda têm aquele preconceito que vai pegar pelo aperto de mão, abraço (ENF-10).

A família é uma peça fundamental né, pra pessoa não ter esse tipo de sentimento, de exclusão, de preconceito, de discriminação, a família é a primeira parte que tem que está apoiando (ACS-2).

\section{HIV/Aids e a sexualidade}

A culpabilização da pessoa na contaminação do HIV/Aids, relacionada ao reforço de que a mesma é adquirida quando cometidos atos socialmente reprováveis, apareceu em destaque. Na significação dos profissionais entrevistados, aqueles que convivem com a infecção são considerados indivíduos que assumiram "comportamentos de risco", ou agiram de forma incorreta, e, por isso, tiveram o desfecho da soropositividade. Isso confirma-se no realce da traição como forma de contaminação, e, sendo vista com repulsa pela maior parte dos sujeitos, fortalece o caráter reprovável ao qual a infecção é associada, bem como há atribuição de juízo de valores aos comportamentos.

Elas sabem que fizeram a coisa errada né, e elas sabem que é uma doença que não tem cura [...] os meninos, as moças; as moças vêm aqui desesperadas, se eles estão desesperados é porque fizeram sexo sem preservativo (D-8).

Tem gente que depende do que ela aprontou ela vem na unidade, quer fazer os exames só pra confirma a suspeita, então quer dizer ela sabe que correu um risco, se arriscou ali, não se precaveu e acabou pegando (AXE-9).

A gente vê na área da saúde que têm mulheres casadas, confia no parceiro e o parceiro traz a doença (ACS-4).

Mantêm-se, ainda, a ideia de grupos de risco, pois, embora iniciassem o raciocínio alegando que todas as pessoas estão susceptíveis, populações especí- 
ficas tomaram lugar em suas falas, demonstrando que estas ainda são vislumbradas como público-alvo da infecção.

Eu acho que todos os grupos estão sujeito à Aids, só que tem um grupo, tem mais risco [...] é idoso que, que não tem assim mais a sua esposa ou seu esposo entendeu?![...] os grupos de homossexualismo, jovens, adolescentes também, donas de casa [...] (ACS-1).

Todos né, assim a prevalência maior ainda continua nos homossexuais, nas lésbicas, nas, nos profissionais do sexo né, mas toda a população em geral ela se contamina através do HIV (ENF-10).

Os discursos obtidos apontam como núcleo central do HIV/Aids o sexo, ou seja, sua forma de contágio e os comportamentos considerados de risco são relacionados a práticas que envolvem o intercurso sexual e, mais especificamente, a quantidade de parceiros, bem como a já citada traição. É pouco expressiva a transmissão por uso de drogas injetáveis, contrapondo-se à realidade territorial da USF investigada, marcada por tal vulnerabilidade. Quando presentes, as mesmas foram tidas como fator que ocasiona o ato de sexo desprotegido ou quantidade de parceiros, facilitando a contaminação pelo vírus e não o contágio pelo ato de usar drogas. Já a transmissão vertical ou por transfusão sanguínea pareceram ignoradas. Isso torna-se ainda mais evidente quando expressam orientações de prevenção do HIV/Aids, limitadas, em sua maioria, ao argumento de uso de preservativo e policiamento de traição.

Eu acho que uma forma da gente, mesmo que seu esposo já seja de idade, assim você tem um bom convívio, seria bom a gente sempre se proteger (ACS-1).

Usando preservativo pode evita isso (ENF-10).

O principal é a prevenção, o sexo seguro (M-13).

Paralelo a tais percepções, a equipe constantemente relatou mudanças ao longo do tempo no modo de ver o HIV/Aids, sendo a informação e o conhecimento sobre o vírus, bem como o trabalho na saúde e convívio com pessoas com essa condição, essenciais para afastar as imagens negativas em relação a mesma.

Quando eu não trabalhava na saúde era uma coisa, assim, que me deixava um pouco assim, opa, não me mistura mesmo [...] entrando na área da saúde, trabalhando com isso, vendo de perto a situação, é uma coisa que, é, esse rótulo, essa coisa caiu por terra, então, porque você consegue enxergar a pessoa além daquilo (ACS-5).
Olha eu acho que, acho que, assim, antigamente, né, a gente que trabalhava com isso assustava [...], eu acho que a gente foi amadurecendo, a gente foi, hoje em dia eu atendo naturalmente um soropositivo, normalmente como se fosse outra pessoa (D-8).

\section{DISCUSSÃO}

Alguns aspectos ressaltaram-se nas entrevistas e permitiram o entendimento das percepções dos profissionais da Saúde da Família em questão. Uma das principais, visto a força de sua representação, foi a "anormalidade" do usuário que convive com HIV/ Aids. O normal é definido socialmente, quando o coletivo de determinado meio classifica as pessoas de acordo com atributos. Aquelas que possuem os atributos desejados são consideradas normais, enquanto os que não se enquadram nesse padrão, desviantes (GOFFMAN, 1963). Nessa perspectiva, uma enfermidade pode ou não ser vista como um desvio a depender do sistema de valores e normas em que o doente está inserido, admitindo, ainda, que os padrões de saúde e doença variam entre as diferentes sociedades e dentro de uma mesma, visto as divergentes posições socioeconômicas e culturais (BIAR, 2015; GOFFMAN, 1963).

Neste estudo, essa construção social atributiva foi afirmada pelos profissionais ao identificarem união estável, fidelidade, poucos parceiros sexuais, o "agir certo", que se estende ao sexo seguro, modelo de vida saudável com exclusão do uso de drogas, bebidas alcoólicas e ausência de "comportamentos de risco", características desejáveis, que, em sua visão, estão ausentes nos indivíduos que convivem com HIV/Aids. Sobressai-se, assim, a caracterização primária do imaginário social relacionada a tabus e morte, quando a irresponsabilidade se apresenta como o principal atributo dos sujeitos que convivem com a infecção, perpetuando e propagando estigma diante da infecção.

Em vista dessa classificação social, contudo, propõe-se, a fim de quebrar o distanciamento do ser normal e anormal, bem como a significação negativa e repulsiva da anormalidade, explicitar um novo paradigma a essa discussão, em que a normalidade se apresenta como um plano abrangente que envolve tanto a saúde quanto a doença; isso porque ela se refere a uma norma de vida, ou jeito de viver, e não há vida sem normas (CANGUILHEM, 2011). Nesse sentido, saúde e patologia são vistas como normais porque ambas apresentam normas. Essas normas, por sua vez, são distintas, sendo a da saúde passível de mudanças e a da patologia não aberta a modifica- 
ções, mantendo obediência restrita a padrões de vida preexistentes em razão de um desequilíbrio orgânico das faculdades humanas em seu sentido holístico (CANGUILHEM, 2011).

Assim, o patológico é normal porque a experiência de existir inclui também a doença, caracterizada por uma nova forma de viver. Recusa-se, então, uma normalidade generalizada que denota um grupo sem diferenças e sem a capacidade de instituir novas normas, o que haveria de negar a essência humana que tem a condição inata de modificar-se internamente a depender da realidade, valores e crenças que a permeia (CANGUILHEM, 2011). Reforça-se, assim, que o normal e o patológico mantêm estrita relação com o sujeito, que, por sua vez, é construído socialmente. Suas vivências o transformam continuamente e, portanto, sua subjetividade nunca é absoluta, mas relacionada a um contexto. Cada um tem sua própria concepção do que seria normal para si e, por isso, não existe uma única normalidade e sim distintas normalidades (CANGUILHEM, 2011).

Nesse sentido, a imposição de padrões de vida resultaria em refutar concepções individuais e limitar a natureza humana. $O$ respeito às diferentes normas, por sua vez, responde às singularidades que caracterizam o indivíduo e é base para o cuidado integral ao usuário, bem como para mudanças efetivas no modelo de atenção aos mesmos. Para entendimento e aceitação das diferentes normalidades é preciso desprender-se dos padrões sociais perpetuados e desconstruir a própria percepção da normalidade, onde a abertura a outros modos de vida, diferentes àquele que o estranha, passe a ser não mais punida, mas vista com naturalidade, o que, de fato, representa.

Somando-se à anormalidade, predominam percepções negativas sobre o convívio com HIV/Aids, com diagnóstico caracterizado por desequilíbrios emocionais, das relações interpessoais e confronte com ideias de sofrimento e finitude, bem como referência ao impacto pessoal, familiar e social, quando consultas regulares e a obrigatoriedade de medicamentos, são percebidas como limitadoras da vida das pessoas que convivem com a infecção (ARANSIOLA et al., 2014; TAQUETTE; RODRIGUES; BORTOLOTTI, 2015). Adiciona-se a comparação do HIV/Aids com câncer. Esta é estabelecida porque ambos suscitam sentimentos relacionados ao perigo, dor, ameaça, limitações e morte. Geram difícil aceitação do diagnóstico e influência semelhante na desestruturação do cotidiano de vida do sujeito que a compartilha e de seu meio. Ocasionam, geralmente, exclusão pelo afastamento social, por medo de contágio ou de lidar com o sofrimento, que, aparentemente, na percepção coletiva, é fator imutável dessas condições (STANGL et al., 2019).

Referente aos obstáculos do convívio com HIV/ Aids, a literatura (RENESTO et al., 2014; TAQUETTE; RODRIGUES; BORTOLOTTI, 2015; TREFFRY-GOATLEY et al., 2016) confirma o preconceito e a exclusão como dificuldades. 0 estigma social sobre a infecção reflete na percepção de isolamento, julgamento e discriminação, impondo sentimentos de culpa, vergonha, ansiedade e tristeza às pessoas que vivem nessa condição. $\mathrm{Na}$ tentativa de evitar que isto ocorra, esses indivíduos acabam por ocultar o diagnóstico para seu meio familiar e afetivo, iniciando o processo de superação e adaptação isoladamente (BEUTHIN; BRUCE; SHEILDS, 2014).

O estigma do HIV/Aids, configurando-se como a principal barreira para prevenção e tratamento da infecção (MBONYE et al., 2016), propõe questionamentos sobre quem o pratica. Embora os trabalhadores entrevistados atribuam sua predominância à família e amigos próximos, excluindo-se desse processo, a análise de seus discursos promulga imersão na perpetuação do preconceito. A evidência desse achado firma-se na percepção de culpabilização da pessoa no contágio à infecção e reducionismo da mesma a indivíduos específicos. Grupos ou comportamentos de risco são conceitos oriundos dos anos 80 do século 20, paralelos à descoberta do HIV/Aids, e são associados a rótulos que geram e reproduzem estigma social. Essas expressões culpam o indivíduo e o colocam como responsável por adquirir o vírus, uma vez que falhou em sua proteção, não considerando que o processo de contágio e adoecimento decorre de aspectos individuais, coletivos e contextuais (GOMES; SILVA; OLIVEIRA, 2011). Nesse aspecto, o termo mais adequado é a vulnerabilidade, pois traduz a complexidade desses fatores à exposição ao HIV (LEAL; COÊLHO, 2016).

Considerando o processo multifatorial, modulado por fatores econômicos e socioculturais, envolvido no contágio da infecção, sabe-se que a Aids não atinge apenas alguns segmentos populacionais, mas está relacionada às chances de exposição dos sujeitos. Assim, a vulnerabilidade é determinada por comportamentos que oportunizam o indivíduo a contrair doenças, ao grau de consciência que tem sobre seus comportamentos e ao seu efetivo poder para transformá-los, considerando-o em sua integralidade e relação com o coletivo (LEAL; COÊLHO, 2016). A concepção de grupos de risco ignora as mudanças epidemiológicas que a infecção adotou ao longo dos anos e se limita a re- 
forçar o estigma, à medida que trata a condição como prevalente em estereótipos sociais marcados pela exclusão.

A declaração de reconstruções simbólicas ao longo do tempo no modo de ver o HIV/Aids, em oposição a percepções estigmatizantes evidenciadas no estudo, demonstra profissionais que usufruem de um discurso politicamente correto sem, no entanto, modificarem-se. Muitos trabalhadores da saúde, mesmo após anos de informação sobre o HIV/Aids, possuem arraigados preconceitos exteriorizados no cotidiano da assistência a esses indivíduos (DANTAS; DANTAS, 2014). Além do mais, outras pesquisas (DANTAS; DANTAS, 2014; ZAMBENEDETTI; BOTH, 2013) contemplam esse achado ao postularem profissionais que também afirmaram mudanças em suas percepções em razão do conhecimento sobre a doença e tratamento, bem como aumento da expectativa e qualidade de vida das pessoas que convivem com a infecção, mas que eram contraditórias no decorrer da entrevista, associando o HIV/Aids com o estigma visto por eles como previamente superado.

Baseando-se na Teoria das Representações Sociais, que visa a compreender a construção do conhecimento compartilhado em determinado grupo a partir da identificação de suas representações coletivas (MOSCOVICI, 2015), pode-se traçar o reflexo dessas acepções na prática do cuidado em HIV/Aids. Ao desvelar os significados da relação entre os sujeitos (profissional-usuário) e o fenômeno, torna-se possível entender o comportamento humano em sua dimensão cognitiva, afetiva e social e, consequentemente, a prática do cuidado exercido. Isso porque as representações sociais guiam as práticas dos profissionais, e seus valores morais manifestam-se fortemente na assistência (MARTINEZ; SOUZA; TOCANTINS, 2012). É no exercício de sua atuação que eles revelam verdadeiramente quem são, pois suas percepções demonstram-se involuntariamente, determinando seu modo de ver o mundo e modulando seu agir perante a sociedade (BARBOSA; TEIXERIA; OLIVEIRA, 2016). Para tanto, o conjunto de representações negativas e o estigma evidenciado entre os trabalhadores entrevistados, é fator potencial para que esta fundamentação simbólica seja retratada no fazer e produzir saúde (NYBLADE et al., 2019).

A perpetuação do estigma em profissionais da saúde permanece porque a base da discriminação do HIV prevalece em suas concepções, a saber: os atributos historicamente intitulados aos indivíduos que convivem com a infecção, marcado predominantemente pela imoralidade sexual - homossexualidade, pros- tituição, quantidade de parceiros e infidelidade. Isso remete a uma sociedade repleta de tabus, que pouco critica seus padrões de regra e dialoga com as variáveis da norma coletiva apregoada, e, como antes de profissionais são seres humanos sociais, estão imersos nos valores que os cercam, reproduzindo-os. Essa realidade demonstra que o conhecimento explícito não parece ser o suficiente para modificar as imagens sobre o HIV, e que para oferecer reconstruções perceptivas é necessário que esteja atrelado à reflexão do conhecimento tácito. Isso torna-se um desafio, uma vez que os profissionais negam qualquer participação no preconceito, e, por isso, não há revisitação de seus conceitos, uma vez que se consideram isentos de tal prática (EW et al., 2018).

A formação profissional e a educação permanente devem estar comprometidas com a urgência em qualificar o cuidado às pessoas que convivem com HIV/Aids. Torna-se necessário o incremento de estratégias de sensibilização que visem o reconhecimento pessoal do arcabouço simbólico estigmatizado e o desenvolvimento da empatia. Debates devem ser realizados em torno do tema, permitindo que os estudantes e profissionais exteriorizem seus valores e percepções, oferecendo espaço para o autoconhecimento e reflexão, elementos indispensáveis para a desconstrução do ser, potencializando a formação de novas percepções para o HIV/Aids (DANTAS; DANTAS, 2014); percepções que não mais ressaltem significados de sofrimento, erro e morte, mas de qualidade de vida, cronicidade, tratamento e novas condições de existência, considerando a singularidade de cada indivíduo. A construção de novas imagens repercutiram no modo de pensar e agir, e, consequentemente, na prática do cuidado para pessoas que convivem com HIV/Aids.

A interiorização de novos significados poderá desmistificar os estereótipos do HIV, possibilitando não somente o empoderamento daqueles que convivem com a condição, mas auxiliando a quebra de barreiras do preconceito social à medida que as novas construções simbólicas são reproduzidas e propagadas. Empoderar, portanto, refere-se à emancipação, quando os indivíduos se aprofundam na perspectiva de serem protagonistas de suas vidas, escolhas e planos, sentindo-se capazes de se autodefenderem e superar os obstáculos do cotidiano. Além disso, como o empoderamento é relacional, ou seja, depende da interação do meio, o influencia em vista da liberdade de valores e rótulos, possibilitando a construção de novas percepções sobre a infecção (MUHLEN; SALDANHA; STREY, 2014). Os profissionais de saúde devem 
favorecer a identificação dos recursos internos de cada usuário, auxiliando em seu processo de emancipação e superação ao HIV/Aids.

Torna-se evidente que, embora sejam constantes os avanços das tecnologias assistenciais perante a infecção, ainda há um longo caminho a ser percorrido no que se refere à significação da mesma, a fim de naturalizar um cuidado integral e respeitoso às subjetivas normalidades. Por fim, entre as limitações do estudo destaca-se a restrição de dados, visto o mesmo ter se realizado apenas com uma equipe multidisciplinar da ESF, impossibilitando amplos e adicionais achados sobre o tema.

\section{CONCLUSÃO}

O desenvolvimento deste estudo possibilitou conhecer e analisar as percepções dos profissionais da saúde da família sobre o HIV/Aids, refletindo e incentivando a criticidade de crenças e valores e como estas interferem na prática assistencial. Observou-se que os trabalhadores da USF apresentaram contradições durante a entrevista, na qual o discurso de afastamento do estigma quanto à doença apareceu em contraste diante dos aspectos de culpabilização da pessoa que convive com HIV/Aids, público-alvo da infecção marcado por indivíduos específicos, associação com sexo e atos ilícitos, bem como anormalidades desses indivíduos e seu tratamento.

É necessário, portanto, que os profissionais de saúde se desconstruam diariamente, mudando sua maneira de pensar e agir perante a infeção, influenciando, assim, a qualidade do cuidado, fortalecido pelas relações interpessoais marcadas pelo vínculo, confiança e respeito. Ressalta-se a necessidade de estudos intervencionais com equipes de saúde, fundamentados na perspectiva da transformação das práticas em direção ao cuidado integral, humanizado e de qualidade.

\section{REFERÊNCIAS}

ARANSIOLA, J. et al. Living well with HIV in Nigeria? Stigma and survival challenges preventing optimum benefit from an ART clinic. Global Health Promotion, v. 21, n. 1, p. 13-22, 2014.

ARANTES, L. J.; SHIMIZU, H. E; MERCHAN-HAMANN, E. Contribuições e desafios da Estratégia Saúde da Família na Atenção Primária à Saúde no Brasil: revisão da literatura. Ciência \& Saúde Coletiva, v. 2, n. 5, p. 1.499-1.509, 2016.

BARBOSA, C. R.; TEIXEIRA, E.; OLIVEIRA, D. C. Representational structure of health professionals about care delivery to people living with HIV/Aids. Invest. Educ. Enferm., v. 34, n. 3, 2016.
BEUTHIN, R. E.; BRUCE, A.; SHEILDS, L. Storylines of Aging With HIV: Shifts Toward Sense Making. Qualitative Health Research, Oct. 2014.

BIAR, L. A. Desvio e estigma: caminhos para uma análise discursiva. Calidoscópio, v. 13, n. 1, p. 113-121, 2015.

BRANDÃO, B. M. G. M. et al. Representações sociais da equipe de enfermagem perante o paciente com HIV/Aids: uma revisão Integrativa. Rev. Enferm. Ufpe, Recife, v. 11, n. 2, p. 625-633, 2017.

CACCIA-BAVA, M. C. G.; MATTOS, A. T. R.; ROCHA, J. S. Y. Atenção básica e a estratégia de saúde da família. In: ROCHA, J. S. Y. Manual de São Paulo e saúde coletiva no Brasil. São Paulo: Atheneu, 2012. p. 65-75.

CALIARI, J. S. et al. Factors related to the perceived stigmatization of people living with HIV. Rev. Esc. Enferm. USP, v. 51, n. e03248, 2017.

CANGUILHEM, G. O normal e o patológico. 6. ed. Rio de Janeiro: Forense Universitária, 2009.

CANGUILHEM, G. O normal e o patológico. 7. ed. Rio de Janeiro: Forense Universitária, 2011.

DANTAS, M. S. et al. Representações sociais do HIV/AIDS por profissionais de saúde em serviços de referência. Rev. Gaúcha Enferm., v. 35, n. 4, p. 94-100, 2014

DANTAS, F. C.; DANTAS, C. C. Valores intervenientes no cuidado do enfermeiro ao cliente com HIV/Aids. Aquichan, v. 14, n. 1, p. 32-40, 2014.

EW, R. A. S. et al. Estigma e teste rápido na Atenção Básica: percepção de usuários e profissionais. Rev. Bras. Promoç. Saúde, v. 31, n. 3, p. 1-11, 2018.

FORSAIT, S. et al. Impacto do diagnóstico e do tratamento de câncer e de Aids no cotidiano e nas redes sociais de crianças e adolescentes. Arq. Bras. Ciên. Saúde. Santo André, v. 34, n.1, p. 6-14, 2009.

GOFFMAN, E. Estigma: notas sobre a manipulação da identidade deteriorada. Rio de Janeiro: Zahar, 1963.

GOMES, A. M. T.; SILVA, E. M. P.; OLIVEIRA, D. C. Representações sociais da Aids para pessoas que vivem com HIV e suas interfaces cotidianas. Rev. Latino-Am. Enfermagem, v. 19, n. 3, maio/jun. 2011.

GUIMARÃES, M. D. C. et al. Mortalidade por HIV/Aids no Brasil, 2000-2015: motivos para preocupação? Rev. Bras. Epidemiol., v. 20, n. 1, p. 182-190, 2017.

LEAL, N. S. B.; COÊLHO, A. E. L. Representações sociais da Aids para estudantes de Psicologia. Fractal: Revista de Psicologia, v. 28, n. 1, p. 9-16, jan./abr. 2016.

MARTINEZ, E. A.; SOUZA, S. R.; TOCANTINS, F. R. As contribuições das representações sociais para a investigação em saúde e enfermagem. Invest. Educ. Enferm., v. 30, n. 1, p. 101-107, 2012.

MEIRELLES, B. H. S. et al. Percepções da qualidade de vida de pessoas com HIV/Aids. Rev. Rene, Fortaleza, v. 11, n. 3, p. 68-76, jul./set. 2010.

MBONYE, M. et al. Test and treat: The early experiences in a clinic serving women at high risk of HIV infection in Kampala. Aids Care, v. 28, n. s3, p. 33-38, 2016. 
MOREIRA, V. et al. Fenomenologia do estigma em HIV/Aids: "coestigma". Mental, Universidade Presidente Antônio Carlos Barbacena, Brasil, v. 8, n. 14, p. 115-131, jan./jun. 2010.

MORIN, E. Os sete saberes necessários à educação do futuro. São Paulo: Cortez; Brasília, DF: Unesco, 2011.

MOSCOVICI, S. Representações sociais: investigação em psicologia social. 11. ed. Petrópolis: Vozes, 2015.

MUHLEN, B. K. V.; SALDANHA, M.; STREY, M. N. Mulheres e o Hiv/Aids: Intersecções entre gênero, feminismo, psicologia e saúde pública. Revista Colombiana de Psicologia, v. 23, n. 2, jul./dez. 2014.

NYBLADE, L. et al. Stigma in health facilities: why it matters and how we can change it. BMC Medicine, v. 17, n. 25, 2019.

OLIVEIRA, D. C. Análise de conteúdo temático-categorial: uma proposta de sistematização. Rev. Enferm. Uerj, Rio de Janeiro, v. 16, n. 4, p. 569-576, out./dez. 2008.

RENESTO, H. M. F. et al. Enfrentamento e percepção da muIher em relação à infecção pelo HIV. Rev. Saúde Pública, v. 48, n. 1, p. 36-42, 2014.

SILVA, R. A. R. et al. Atenção à saúde de portadores de HIV: avaliação de usuários. Rev. Fund Care On-line, v. 9, n. 1, p. 21-27, jan./mar. 2017.

STANGL, A. L. et al. The Health Stigma and Discrimination Framework: a global, crosscutting framework to inform research, intervention development, and policy on health-related stigmas. BMC Medicine, v. 17, n. 31, 2019.

TAQUETTE, S. R.; RODRIGUES, A. O.; BORTOLOTTI, L. R. Infecção pelo HIV em adolescentes do sexo feminino: um estudo qualitativo. Rev. Panam Salud Publica, v. 37, n. 4/5, p. 324-29, 2015.

TREFFRY-GOATLEY, A. et al. Understanding Specific Contexts of Antiretroviral Therapy Adherence in Rural South Africa: A Thematic Analysis of Digital Stories from a Community with High HIV Prevalence. Plos One, Feb. 2016.

UNAIDS. United Nations Programme on HIV/AIDS. Joint United Nations Programme on HIV/AIDS. Global Aids Update. Geneva, Switzerland, 2019.

VILIARINHO, M. V.; PADILHA, M. I. Percepção da Aids pelos profissionais da saúde que vivenciaram a epidemia durante o cuidado prestado às pessoas com a doença, em Florianópolis (SC), Brasil (1986-2006). Ciência \& Saúde Coletiva, v. 19, n. 6, p. 1.951-1.960, 2014.

ZAMBENEDETTI, G.; BOTH, N. S. "A vida que facilita é a mesma que dificulta". Estigma e atenção em HIV-Aids na Estratégia Saúde da Família - ESF. Fractal, Rev. Psicol, v. 25, n. 1, p. 41-58, jan./abr. 2013. 